A R R TII C C U L O O D E I $N$ VES $S$ TI G A C I Ó $N$ $\begin{array}{llllllllllllllll}C & I & E & N & T & I & F & I & C & A & Y\end{array}$

TEE C N O L L Ó G G I C A

\title{
TRABAJAR SIN ROMPER EL MOLDE: DISCRIMINACIONES EN ESPACIOS LABORA- les a personas lgbt en Cartagena de Indias y BarRanquilla, Colombia
}

WORKING WITHOUT BREAKING THE MOLD: DISCRIMINATION IN LABOR SPACES FOR LGBT COMMUNITY IN CARTAGENA AND BARRANQUILLA, COLOMBIA

\section{Por: Alexander Pérez Álvarez*}

Recibido: 15 de marzo de 2017 - Aprobado: 15 junio de 2017

*Trabajador Social

de Hábitat, doctorando

en Antropología. Do-

cente-Investigador de

la Facultad de Ciencias

Sociales y Educación

Universidad de Car-

tagena. Integrante del

Grupo de Investigación

Grupo de Investigación

Cultura, Ciudadanía

y Poder en Contextos

Locales y Socio e inves-

tigador de la Corpora-

ción Caribe Afirmativo.

\begin{abstract}
RESUMEN
Este artículo identifica algunas discriminaciones que a diario vivencian personas LGBT en el mundo del trabajo, en dos de las principales ciudades del Caribe colombiano. Estas acciones están encriptadas y justificadas en un contexto y discurso patriarcal, cargado de prejuicios y estigmas frente a la diversidad sexual e identidades de género. Una sociedad que a pesar de avances en materia jurídica y normativa sigue representando y relacionando las sexualidades no heteronormativas, con conductas cercanas a lo patológico y como prácticas peligrosas al orden moral preestablecido.
\end{abstract}

Estas discriminaciones pueden ser interpretadas como violencia y dispositivos de control y disciplinamiento de los cuerpos que vulneran derechos y por sus características soterradas terminan casi siempre silenciadas, ocultas y naturalizadas socialmente.

Para adentrarse a ese complejo mundo, metodológicamente se parte de elegir una perspectiva cualitativa de investigación social, el trabajo etnográfico sustentado en un diálogo cara a cara, de recuperación de memoria y la percepción de la experiencia vivida, se convierten en cartas de navegación para problematizar y desnaturalizar dichas acciones.

Palabras clave: diversidad sexual e identidades de género, discriminaciones, mundo del trabajo, personas LGBT.

\begin{abstract}
This article identifies some of the discriminations experienced daily by LGBT community in the world environment in two of the main cities of the Colombian Caribbean. These actions are encrypted and justified in a patriarchal context and discourse, loaded with prejudices and stigmas against sexual diversity and gender identities. Despite advances in legal and normative matters, this society continues representing and relating the non-heteronormative sexualities with behaviors close to the pathological and dangerous practices to the pre-established moral order.
\end{abstract}

These discriminations can be interpreted as violence and devices of control and discipline of the bodies that violate rights and because of their buried characteristics end up silenced, hidden and socially naturalized. 
The methodology to go deeper into that complex world, starts by choosing a qualitative perspective of social research, the ethnografic work supported by a face to face dialogue, memory recovery and the perception of personal and lived experiences, which becomes in navigational charts to problematize and denaturalize such actions.

Keywords: sexual diversity and gender identities, discriminations, work environment, LGBT community.

\section{Introducción}

«Mis amigos me llaman cariñosamente la niña Luisa y cuando nos vemos en nuestras casas las plumas vuelan al viento sin medida. Soy un hombre que desde que nació sabe que soy gay, pero las plumas y la maricada no pueden notarse cuando salgo para el trabajo y llego a la oficina. Es que nadie le creería... a un ingeniero maricón y afeminado (...) en el trabajo, todo el tiempo estoy pendiente de comportarme como un hombre, bien hombre, sin romper el molde, de no hacer nada raro, para no generar sospechas». (Luis, 27 años, Barranquilla, noviembre de 2016).

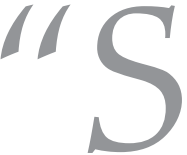
in romper el molde" metáfora que referencia a no salirse de la norma social, "mostrar lo que los demás esperan ver en uno"; este es un ejemplo, en las ciudades de Cartagena y Barranquilla, en el Caribe colombiano, de conductas y actitudes que deben asumir personas LGBT $^{1}$ en sus lugares de trabajo. Ello para intentar protegerse de un sinnúmero de violencias a las que se exponen cuando se autoreconocen públicamente o se hace visible una orientación sexual y/o identidad de género por fuera de la norma heteronormativa. Estas violencias se sustentan en la reproducción de un discurso binario y naturalizado de la sexualidad y son acciones que en la mayoría de los casos, terminan normalizándose en la vida cotidiana y aunque deje huellas en sus cuerpos en muchas de las personas que participaron de este ejercicio de investigación.

\section{Proceso metodológico}

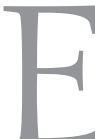

sta investigación de tipo cualitativo, ha estado fundamentada en algunos de los planteamientos de Merlau Ponty (1997) desde un enfoque fenomenológico, en el que la realidad además de ser una producción intersubjetiva e individual del investigador es también un producto social vinculado a un sistema de signos cambiantes desde donde se hace posible configurar un sentido interrogativo y experiencial, en el que las vivencias cobran sentido en los relatos y reflejan el mundo interno de los sujetos.
1 La sigla LGBT, la empleamos para referirnos a personas lesbianas, gais, bisexuales y trans, es utilizada en términos jurídicos y políticos. Se propone como una categoría para la exigibilidad de derechos en el contexto del reconocimiento a la diversidad sexual y de género (Pérez, Correa y Castañeda, 2013). Es una clasificación jurídica, más que un concepto socio antropológico. En esta artículo si bien, incluimos en la sigla a personas bisexuales, en los análisis esta orientación sexual no se aborda, debido a que en la experiencia de campo no se encontraron personas que se autoreconocieran como tal 
2 Esta investigación de la que el autor de este artículo se vincula como investigador, permite develar y contrastar datos de discriminación y exclusión hacia personas LGBT en el mundo del trabajo en tres ciudades del país: Cartagena, Bogotá y Medellín. Violencias ocultas, enrarecidas por el prejuicio y estereotipos que a manera de imágenes congeladas operan en los imaginarios colectivos y reproducen estas acciones revictimizando a los sujetos. drid. Págs $219-273$.
El trabajo de campo desarrollado por el autor se llevó cabo en dos periodos de tiempo, el primer momento, en el año 2013 en el marco de la investigación «Raros: Diversidad sexual y mundo laboral. Discriminación y exclusión» (2013)² y el segundo momento, en el año 2016, a través de un proceso de consultoría en espacios para construcción de paz y desde allí se busca reconocer en estos contextos condiciones de vida de personas LGBT y es el acceso al trabajo y el desempleo una de las exclusiones significativas que viven.

Esta reflexión se centra en el análisis de algunos hallazgos encontrados en las ciudades de Cartagena y Barranquilla, en el Caribe colombiano. Estas ciudades, presentan el mayor índice de desarrollo industrial, comercial y de oferta de servicios en la región y cuentan según el DANE (2016) con cifras bajas de desempleo en el país. Para la recolección de la información se acudió a la observación directa en espacios laborales, entrevistas a profundidad -bajo la técnica de bola de nieve- con personas que se autoreconocen como lesbianas, gays y trans; también se realizaron entrevistas a algunos empleadores, líderes de organizaciones sociales y sindicales para conocer sus percepciones desde otras orillas. Estas técnicas a la vez se acompañaron de grupos de discusión con personas e integrantes de algunas de las organizaciones sociales LGBT que existen en las ciudades mencionadas.

\section{Estructura del artículo}

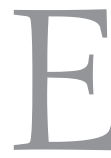

ste artículo se estructura en dos apartados y unas conclusiones. En primer lugar se realiza un acercamiento conceptual a las nociones de diversidad sexual y allí se presenta un debate inicial acerca de cómo se constituye el prejuicio en las sexualidades y cuerpos que rompen con las lógicas binarias del género, ello se apoya en una aproximación a la categoría de discriminaciones y de trabajo.

En segundo lugar, en el apartado que lleva como título "que no se note la maricada" se presentan hallazgos significativos de este proceso investigativo, reconociendo acciones y formas particulares de discriminar y excluir al otro/a por su orientación sexual, identidad o expresión de género. En ese sentido se analizan las acciones y prácticas identificadas en este proceso investigativo, como son: uso de un lenguaje denigrante, roles estereotipados, autoexclusión de espacios laborales, eliminación en los procesos de selección, aplazamiento en la construcción del género, entre otras. 


\section{Aproximaciones conceptuales}

$\gamma$ omo acercamiento conceptual, considero clave comenzar planteando que cuando hablamos de diversidad sexual hacemos referencia a una categoría que permite comprender diversas formas de expresar la afectividad, el erotismo, el deseo y las prácticas amorosas, así como asumir identidades y preferencias que no están limitadas a lo que comúnmente conocemos como heterosexualidad o relaciones de pareja y erótico afectivas entre mujeres y hombres. Es una carta de navegación para descubrir y reconocer un universo de múltiples posibilidades de asumir y vivir la sexualidad (Caribe Afirmativo, 2013).

Esta categoría cuestiona la idea determinista de que existe solo una manera de vivir la sexualidad -la heterosexual- y hace visible nuevas formas de expresarla, destacando que ninguna de ellas debe ser objeto o motivo de discriminación, mientras se de en el marco del respeto a la integridad y derechos de las personas.

Nuestra sociedad está constituida por unos esquemas simbólicos y sistemas de opresión que se reproducen en escenarios como la familia, la escuela y el trabajo. Para Nancy Fraser (1997) estos esquemas y sistemas se reproducen desde dos perspectivas. La primera re-produce una estructura patriarcal que opera bajo un patrón institucionalizado desde el cual se privilegia lo masculino al tiempo que devalúa aquello codificado a la mujer y a lo femenino y heterosexista, y la segunda, establece en la sociedad unas normas culturales autoritarias que promueven exclusivamente la heterosexualidad como algo naturalizado e inviolable. (Fraser, 1997).

La sociedad a través de sus instituciones, reproduce una injusticia material y simbólica que se materializa en un NO reconocimiento pleno del sujeto a nivel familiar, jurídico, político y social. Estas injusticias materiales y simbólicas que afrontan a diario las personas que des-obedecen la normatividad impuesta, es posible develarlas en una serie de acciones que podríamos nombrar bajo una categoría como violencia simbólica, noción acuñada por Bourdieu (2000) para referirse a acciones de negación, sumisión, desvalorización o invisibilización hacia un otro que está por fuera de una sociedad androcentrista y estructurada en una dominación masculina.

Según Bourdieu (2000) la dominación masculina presupone que las actividades y actitudes tanto de mujeres como de hombres, están marcadamente 
3 En el caso de Colombia, la Corte Constitucional (Sentencia T-098 de 1994) define la discriminación como:

«Un acto arbitrario dirigido a perjudicar a una persona o grupo de personas con base principalmente en estereotipos o prejuicios sociales, por lo general ajenos la voluntad del individuo, como son el sexo, la raza, el origen nacional o familiar, o por razones irrelevantes para hacerse acreedor de un perjuicio o beneficio como la lengua la religión o la opinión política o filosófica (...) El acto discriminatorio es la conducta, actitud o trato que pretende-consciente o inconscientemente- anular, dominar o ignorar a una persona o grupo de personas, con frecuencia apelando a pre concepciones o prejuicios sociales o personales, $y$ que trae como resultado la violación de sus derechos fundamentales. Constituye un acto discriminatorio, el trato desigual e injustificado que, por lo común, se presenta en el lenguaje de las normas o en las prácticas institucionales o sociales, de forma generalizada, hasta confundirse con la institucionalidad misma, o con el modo de vida de la comunidad, siendo contrario a los valores constitucionales de la dignidad humana y la igualdad, por imponer una carga, no exigible jurídica ni moralmente, a la persona». diferenciadas por su género; en este sentido, podría afirmarse que la división sexual es un principio básico de la violencia simbólica en este tipo de estructura. Este principio de diferenciación sexual es adoptado y reproducido desde la base de lo familiar, mediante disposiciones que se hacen pasar como naturales, al ser incorporadas y programadas en el juego simbólico del lenguaje, del sentido común, o de lo dado por descontado; de esta manera, el Estado, la iglesia, el trabajo o la escuela, son instituciones que se configuran y reconfiguran simbólicamente, para perpetuar y reafirmar ese principio de diferenciación sexual que se reproduce desde el nicho familiar y que desde las investigaciones sociales se hace necesario des-historizar.

Adicional a estos planteamientos, Judith Butler (1993) considera que las violencias hacia las personas LGBT se debe fundamentalmente a que la sociedad también ha producido desde unos discursos hegemónicos, unas maneras direccionales frente al cómo debe asumirse la sexualidad; dónde opera una idea ideologizada que establece de manera arbitraria, una coherencia entre el sexo anatómico y el género; en esa medida quien rompa con esa coherencia estándar es considerado ininteligible, como alguien que produce extrañeza, un abyecto, alguien humillable, un ser que amenaza la pretensión de tradición natural por lo que hay que mantener alejado, porque para una sociedad linealmente esencializada alguien que subvierta la norma sexual y la legitimidad de ese orden hegemónico heterosexual y de dominación masculina -en términos bourdeanos- sencillamente, es amenazante.

Para Butler (2006) las normas de género solo funcionan exigiendo la encarnación de algunos ideales de femineidad y masculinidad, que casi siempre van unidos a la idealización de la unión heterosexual. Desde su enfoque teórico, la orientación sexual, la identidad sexual o la expresión de género son el resultado de una construcción social, histórica y cultural que trasgrede el orden natural establecido y rompe con la concepción universalista del sujeto, la esencialización y naturalización de roles sociales y sexuales.

Estos discursos permean prácticas, y rituales y reproducen en las dinámicas institucionales como el mundo del trabajo, discriminaciones hacia aquellas personas que irrumpen con roles preestablecidos y que por ese motivo deben estar en la periferia.

Frente a la noción de discriminación es un campo de análisis que en el caso de los estudios de la jurisprudencia latinoamericana ${ }^{3}$ se establece en un 
marco de diferenciaciones entre acciones de discriminación y acciones de exclusión. María Mercedes Gómez (2008) establece por discriminación toda acción humana en la que se brinda un trato de inferioridad a una persona o colectividad por motivos raciales, religiosos, sexuales o políticos; en esa perspectiva, la discriminación debe de entenderse como cualquier práctica que pretenda jerarquizar y/o establecer identidades, actos o acciones como superiores frente a otras que serían reconocidas como inferiores, en otras palabras, busca determinar la superioridad o inferioridad sobre otros.

La exclusión por el contrario, es definida como una acción que descarta, rechaza o niega la posibilidad de alguna cosa, puesto que considera que dos cosas juntas son incompatibles; es decir, es una noción que muestra la incompatibilidad entre los diferentes elementos; según esta autora las prácticas de excluir, suprimen y tratan de eliminar aquello que es incompatible o que amenaza la existencia presente y futura.

Ahora bien, más allá de esa diferenciación propuesta por Gómez en el ámbito jurídico, donde persiste una lógica lineal con fronteras y niveles; es posible adentrarse desde una perspectiva antropológica y referirnos a esta categoría ya no en un plano singular, sino en plural como discriminaciones, en tanto no existe una sola forma, sino que por el contrario, son diversas y numerosas (Machín, 2013).

En este sentido, podría plantearse que las discriminaciones en sus múltiples manifestaciones son fenómenos multidimensionales, implican lógicas y dinámicas interrelacionadas entre sí, generalmente de forma no lineal, ni determinista, adquiriendo "una centralidad inabarcable de sentidos posibles» (Machín, 2013:2).

Asimismo, las discriminaciones son acciones que no solo varían en el espacio-tiempo sino que como lo plantea Passeron (2011) son indisolubles de circunstancias determinadas de lugar y tiempo. Según este autor, si analizamos las discriminaciones como hechos sociales, ineluctablemente deben referirse a un contexto espacio temporal específico, sin desconocer que un mismo fenómeno humano se inscribe en varios contextos de manera simultánea. Pero este espacio- tiempo, es social y en ese sentido, incluye diversidad de coordenadas que tienen que ver con relaciones económicas, políticas, jurídicas, culturales, de poder y de resistencia. Coordenadas que como plantea Orther (2009) están inmersas en relaciones asimétricas de 
4 Vease: Chung (1998), OIT (2012), Caribe Afirmativo (2013) e INADI (2016).

5 Si bien es casi imposible plantear un consenso frente a una noción como cultura; en este artículo optamos por una aproximación contraria al fundamentalismo cultural, que paradójicamente en un mundo globalizado, sigue legitimando la exclusión, establece fronteras fijas y desde un orden administrativo y político lleva a que grupos y personas en este caso LGBT, sean cosificadas y estereotipadas, fabricando imágenes y distancias simbólicas entre modos de ser y estar. Al respecto Véase: Chakrabary (2008) y Orther (2009). poder y el mundo del trabajo es un escenario propicio donde se reproducen dichas asimetrías.

Algunos estudios ${ }^{4}$ desde hace más de tres décadas vienen relacionando la diversidad sexual y el mundo del trabajo, centrando el análisis en esas violencias y discriminaciones que en la vida cotidiana enfrentan y afrontan las personas LGBT, analizar discriminaciones, plantear estrategias de enfrentamiento o analizar la interseccionalidad en las practicas asimétricas constituidas socialmente son temas que estas investigaciones han venido desarrollado y que de alguna u otra manera se constituyen en un sustento previo para las reflexiones aquí planteadas y develan además que la heteronormatividad como modelo hegemónico en el mundo del trabajo persiste y reproduce en las sociedades occidentales, no es un asunto exclusivo al Caribe colombiano pero si tiene matices particulares dependiendo de los contextos.

En esa misma vía, es pertinente señalar que las discriminaciones se alimentan y mantienen a través de dispositivos culturales ${ }^{5}$ que actúan en un «juego» permanente de poder, negociación, lucha y resistencia. En este sentido, al analizar discriminaciones hacia personas LGBT en el mundo del trabajo, se encuentra que dichas acciones se encriptan en un sistema cultural que determina identidades sexuales y las excluye a las periferias sociales.

En esta perspectiva la relación trabajo-diversidad sexual y de género, nos lleva necesariamente a preguntarnos por derechos para las personas LGBT y ello implica transformar la igualdad jurídica en igualdad real, que no es otra cosa que garantizar en la cotidianidad ámbitos laborales respetuosos de la diversidad sexual y de género. Si bien los cambios legislativos en Colombia a manera de sentencias de la Corte, significan un gran avance, en las prácticas sociales continúan arraigados prejuicios y estereotipos que le dan marco a la discriminación y que es necesario revertir. Así, en los contextos laborales sigue existiendo una tendencia a invisibilizar o borrar aquellas identidades que se alejan de la heteronormatividad. (INADI, 2016).

\section{Que no se note la maricada}

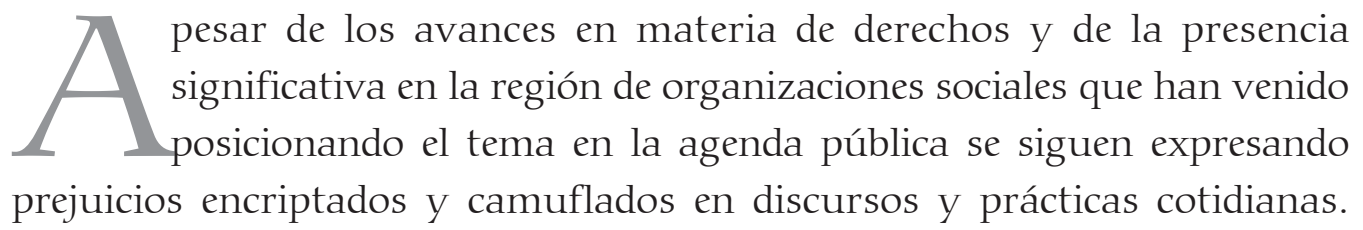


Los procesos y acciones de inclusión generalmente no logran trascender a la garantía de derechos sociales y terminan quedándose solo en el plano de los discursos de respeto a la construcción de identidad y autoafirmación. (Pérez, Corea \& Castañeda; 2013).

En el proceso investigativo desarrollado se ha encontrado una serie de acciones que las personas gays y lesbianas asumen en el mundo del trabajo, para resistir posibles señalamientos; el autocontrolarse, camuflar la sexualidad o esconderse, son estrategias de ocultamiento de una sexualidad que en muchos espacios laborales debe mantenerse oculta para poder acceder y permanecer sin ser una posible víctima de violencias en el trabajo. De otra parte, para aquellas personas que su expresión de género no les permite ocultarse, se ha encontrado que mayoritariamente se inscriben como únicas opciones en el trabajo informal, en una economía del rebusque, donde además opera una segmentación de oficios.

El trabajo es parte esencial de un entramado institucional moderno que opera como disciplina y dispositivo para ejercer control sobre las personas y sus cuerpos, desde allí se determinan unos símbolos y unas conductas que de manera lineal definen comportamientos y legitiman acciones; en ese sentido Foucault (2002) ubica la noción del "cuerpo de los condenados" y de los "cuerpos dóciles"; en la primera, se refiere a un cuerpo inmerso el campo político donde las relaciones de poder que operan sobre él, le obligan a efectuar ceremonias y le exigen ciertos signos y en la segunda, señala que es dócil un cuerpo que puede ser sometido, utilizado, trasformado y perfeccionado. Ahora bien, las personas LGBT en el mundo del trabajo y concretamente para acceder a un empleo, las personas entrevistadas plantean que deben asumir la condena de vivir una identidad ajustada a las lógicas binarias de la sexualidad, sus cuerpos deben disciplinarse y ajustarse, sin romper moldes preestablecidos, o de lo contrario solo queda como lugar de realización las economías del rebusque e informales.

Para muchas personas gays, lesbianas y trans sus cuerpos no pueden ser regulados, pues su construcción y expresión de género es disidente del orden regular y disciplinar que determina la corporalidad en una lógica binaria de lo masculino y lo femenino; en este sentido, en los lugares de trabajo la población LGBT, ante la imposibilidad de tener un cuerpo dócil, se encuentra y tiene que afrontar una serie de discriminaciones y violencias. 
Las discriminaciones en el mundo del trabajo operan en la mayoría de veces, desde dos estrategias, la primera se presenta por medios de dispositivos sutiles y soterrados, dirigidos fundamentalmente a aquellas personas que «pueden esconder o camuflar» su orientación sexual y construir una identidad en un cuerpo dócil que sirve de tranquilizante a un orden institucional marcado por roles binarios preexistentes. Por la posibilidad que tienen de mimetizar su cuerpo y de ocultar su opción sexual no heterosexual o la elección de no hacerla evidente desde su corporeidad, asumen una vida oculta y una constante tensión y temor de ser descubiertos; sin embargo, ello se convierte en una acción de resistencia, una opción de sobrevivencia y un mecanismo de autocontrol para poder vincularse y permanecer en los espacios laborales; aunque ese «esconderse» lleva a que se le vulneren muchos de sus derechos conexos.

En un segundo plano, se encuentran aquellas acciones que están dirigidas fundamentalmente hacia aquellas en quienes su expresión de género, es decir, personas cuya feminidad o masculinidad choca con el orden mimetizado, por la construcción normativa y binaria del género en la que lo masculino es asociado exclusivamente al hombre y lo femenino a la mujer. Estos cuerpos que «rompen el molde» son concebidos como rebeldes, trasgresores de la disciplina; como receptores de dicha exclusión, encontramos a personas trans, hombres gays femeninos y mujeres lesbianas masculinas, quienes por romper ese molde regulador del cuerpo quedan por fuera de la lógica formal de la economía.

"Ser trans, no ha sido fácil. A mi así nadie me da trabajo, creen que soy ladrona o delincuente... a veces yo me deprimo porque creo que toda la vida voy a seguir haciendo esto. Que no es fácil, uno recibe aquí muchos golpes... Que la policía te persigue... en fin mire lo que le conté... esas puñaladas que me metieron me dejaron un miedo. Yo a veces camino por ahí sola y voy mirando que pa' todo lado... es que como si le tuvieran rabia a uno. Mi vida es así, estar aquí en las noches... me levanto a las dos o tres y a pensar en que ya viene la noche. Mi sueño es ir a Italia, allá les va muy bien en este trabajo, quiero ir para ahorrar y comprar una casita para mi mamá, aunque casi no la veo, ella de alguna manera siempre me ha apoyado".

(Entrevista mujer trans, Barranquilla, diciembre de 2016).

Para no ser víctimas de estas acciones discriminatorias las personas LGBT entrevistadas, manifiestan que acuden a estrategias como el ocultamiento y 
el autocontrol; mantener en silencio su orientación sexual o el ocultamiento o aplazamiento de la identidad de género. "yo me lo guardo, me lo oculto", pareciera ser una premisa de control en los espacios laborales que permite no llegar a perder los "privilegios" que se obtienen al contar con un trabajo o empleo formal.

El autocontrol o aplazamiento para no hacer pública la orientación sexual, posibilita estrategias de sobrevivencia como "no caer mal en el grupo de compañeros de trabajo", o manejar una posición de "no preguntes, no digo y ya, este es mi espacio laboral y no lo vínculo con las otras dimensiones de mi vida y no tienen por qué saber que también es un derecho a la intimidad". (Entrevista hombre gay, Cartagena- noviembre de 2016).

En el cuadro 1 se identifican algunas discriminaciones encontradas en esta investigación, dirigidas de manera particular a hombres gais, mujeres lesbianas y personas trans, las cuales posteriormente se describen a partir de las experiencias narradas. Es clave decir que estas operan de manera interdependiente, por ejemplo, a la burla, se le acompaña con presión, acoso u otras acciones; sin embargo, en términos metodológicos pueden clasificarse diferenciadamente y de esta manera presentar una aproximación cartográfica.

\section{Cuadro 1. Discriminaciones hacia personas LGBT en el mundo del trabajo en el Caribe colombiano}

\begin{tabular}{|l|l|l|l|}
\hline Tipos de discriminaciones /Identidades & Hombres gay & Mujeres lesbianas & Personas trans \\
\hline $\begin{array}{l}\text { Uso de lenguaje injurioso, denigratorio y } \\
\text { prejuicioso }\end{array}$ & & & \\
\hline Roles sociales y estereotipados & & & \\
\hline Detrimento en condiciones laborales & & & \\
\hline Hostilidad en el ambiente laboral & & & \\
\hline $\begin{array}{l}\text { Trabajar más horas de las estipuladas en el } \\
\text { contrato y aplazamiento de vacaciones }\end{array}$ & & & \\
\hline Éxito auto-forzado & & & \\
\hline Autoexclusión de espacios laborales & & & \\
\hline Adscripción solo a lugares de trabajo sexual & & & \\
\hline Calle como forma de rebusque & & & \\
\hline $\begin{array}{l}\text { Economía informal como única opción para } \\
\text { genera ingresos }\end{array}$ & & & \\
\hline
\end{tabular}

Fuente: trabajo de campo 2013- 2016 (Cartagena y Barranquilla). 
Uso del lenguaje: El uso de palabras o conceptos para denigrar al otro, se fundamenta en prejuicios sociales y sexuales que se han instaurado en la cultura y que la sociedad emplea para otorgar un sentido despectivo. El chiste, la burla, escuchar comentarios como que "los gays son pervertidos", "las lesbianas les hace falta macho" o que las personas "trans son peligrosas y un mal ejemplo para la sociedad"; se convierten en muchos espacios laborales en prácticas discursivas que a diario vivencian las personas LGBT en sus lugares de trabajo. En ocasiones se utilizan refranes que asocian ser "marica" con ser tonto; como un dicho cartagenero que se refiere a "marica el último", o la expresión "ni que yo fuera marica" utilizada con frecuencia en Barranquilla.

Adicionalmente, cabe señalar que las personas LGBT entrevistadas, expresan que perciben dichos comentarios como algo naturalizado en la cotidianidad y no lo asumen como una actitud discriminatoria, ello lleva a que las mismas personas terminen en ocasiones, legitimando dichas prácticas e incluso las reproducen para evitar que se les asocie con dicha población.

"Yo sé que en esta oficina se refieren a mi como la marimacha o la machorra, yo hasta me acostumbré, mé hago la que no es conmigo y así me evito más problemas. Mi vida personal no la toco aquí, así nos toca vivir a las personas como yo".

(Entrevista mujer lesbiana, Barranquilla, diciembre de 2016).

"Yo en la oficina soy todo un hombre, es que no me gustaría que me traten como el marica; yo veo a mis compañeros de trabajo como se dirigen a los gay y la verdad me da mucho susto que algún día se enteren".

(Entrevista hombre gay, Cartagena, Diciembre de 2016).

Roles sociales estereotipados: En las relaciones laborales, los roles sociales actúan como patrón de ordenamiento; sin embargo, en el caso de las personas LGBT, estos se configuran como escenarios propicios para promover y legitimar actitudes de discriminación hacia ellos y ellas. Estos operan como pautas de conducta que fuerzan a las personas a aceptar ciertos espacios y negarles la posibilidad de acceder a otros, es decir, se parte de una idea preconcebida de que las personas gay, lesbianas o trans, son buenas para ciertos oficios pero no para otros.

"En mi empresa no hay problema con los gay siempre y cuando se comporten bien en el trabajo, yo trato de ubicarlos en puestos en los que 
no tengan mucho contacto con los usuarios; y con la psicóloga, evitamos contratar personas amaneradas, para evitar la burla pública y la mala imagen de la empresa".

(Entrevista Gerente EPS, Cartagena, 2013).

Los prejuicios socialmente construidos hacia las personas LGBT han generado una serie de creencias que llevan a definir actividades, profesiones y prácticas para hombres gay, mujeres lesbianas y personas trans; un asunto esencializante, homogenizante y a la vez, excluyente y cosificante. Si bien, podría ser anacrónico creer que existan empleos u oficios para personas LGBT y que las capacidades y responsabilidades en el tema laboral estén asociadas a la orientación sexual o a la identidad de género, en la cotidianidad del mundo del trabajo pareciera más común de lo que uno creería, asociar a los gays a actividades vinculadas con las artes plásticas, la decoración o la moda; y por ello también, se han generado espacios laborales en los que las personas gays no son reconocidas, son rechazadas en las fuerzas militares y en el sector educativo.

En el caso de las mujeres lesbianas se les asocia con oficios rudos en la informalidad como la venta de productos y a nivel profesional en la ingeniería o carreras afines, sin embargo, siguen siendo más invisibilizadas laboralmente que los hombres gay; el caso en el que persiste mayor estereotipación es para las personas trans a quienes la sociedad sigue ubicando en espacios vinculados al trabajo sexual y a las peluquerías.

Detrimento en condiciones laborales: Expresada en hostilidad en el ambiente laboral, trabajar más horas de las estipuladas en el contrato, imposibilidades de ascenso y movilidad laboral y éxito autoforzado.

En el caso de mujeres lesbianas se habla del temor a sufrir acoso sexual y una práctica poco documentada pero que sigue reproduciéndose que es la violación correctiva. Los trabajos que requieren movilidad y las posibilidades de ascenso en el trabajo son negados en muchas ocasiones porque la orientación sexual puede ser vista como un mal ejemplo; todo ello ha obligado a que a las personas gay y lesbianas, sientan que tienen que esforzarse más, lograr visibilidad por su buen desempeño para que ello opaque o visibilice sus gustos sexuales. 
"Para mí ha sido difícil encontrar trabajo en mi profesión, siento que cuando voy a una entrevista al mírarme como que se decepcionan, como que esperan que una mujer comunicadora, sea no sé qué? ... como alguna presentadora. Yo siempre visto así como me veo, algo masculina y eso es un problema en una sociedad que le pide a la mujer seguir ciertos estereotipos de belleza. Yo tuve una experiencia muy traumática y por lo que me han contado mis amigas no he sido la única y es que los hombres hetero, siguen creyendo que somos lesbianas por falta de macho y si... que con un macho como que una se cura, eso creen ellos y eso es una idea generalizada que nos pone a nosotras en mucho riesgo".

(Entrevista Mujer lesbiana, Cartagena, diciembre de 2017).

Existen discriminaciones, menos sutiles y más directas que validan y se legitiman en exclusiones hacia la población LGBT en espacios laborales; un hecho social que no podría ser analizado solo como un asunto de marginación o de falta de integración como lo han planteado los teóricos de la sociología funcionalista; puesto que muchos de ellos y ellas pueden estar integrados a la sociedad pero son invisibles para los sistemas funcionales, porque no cuentan con las condiciones exigidas para ser tenidos en cuenta (Luhmann, 1995).

En esta investigación la exclusión laboral hacia la población LGBT se entiende desde la perspectiva de Nancy Frazer (1997) y Le Blanc (2007) como un dispositivo de una acción estructural que expresa dos formas de injusticia: una de orden socioeconómico y la otra culturalsimbólica. En la primera se adopta una forma de explotación y marginalidad y en la segunda, una negativa de reconocimiento del otro a quien por prejuicios sociales se le despoja del sí mismo, se le priva de su voz y le adhiere una máscara en su rostro.

Ser tratado de manera precaria en el mundo laboral, es quedar rezagado en las periferias de la sociedad, en un modo de vida fantasmático, privado de unas bases potenciales para poder vivir y no solo subsistir. En este sentido, la precariedad está también explícita cuando al Otro se representa como inútil, inmoral, como un peligro social; al que hay que dominarle, presionarlo para que se oculte y para ello que mejor que construir relatos míticos y caricaturescos sobre su vida.

Los hombres gay con una expresión de género femenina, las mujeres lesbianas con una expresión de género masculina y las personas que se autoreconocen como trans hacen parte de esas acciones de precarización en el mundo del 
trabajo, su identidad de género los excluye de los ámbitos formales de la economía.

Las personas participantes de este proceso de investigación, reconocen una trama compleja de dispositivos, actitudes, acciones y consecuencias directas e indirectas en las que por el prejuicio sexual se desconoce las habilidades, potencialidades y competencias de la persona; estas pueden clasificarse temáticamente en: autoexclusión, eliminación en el proceso de selección, aplazamiento de la deconstrucción de género, autoempleo forzado, la calle como forma de rebusque y prostitución.

Autoexclusión de espacios laborales. Se entiende por autoexclusión en esta investigación el renunciar a incluirse a un campo laboral en el que en principio la persona podría participar porque cuenta con las habilidades para ello, pero que prefiere renunciar porque lo asocia con vivencias de eliminación, excepción y supresión; o porque ha interiorizado creencias y actitudes de rechazo de la sociedad lo que desemboca en sentimientos de auto-estigmatización que termina en conductas de auto-exclusión (Pérez, Correa \& Castañeda, 2013) .

Una sociedad excluyente con las personas que construyen su cuerpo e identidad de género por fuera de la normativa heterosexista lleva a que la vida de esta población se desarrolle en una esfera periférica y de exclusión constante. Los bajos niveles educativos que presenta este grupo poblacional, debido a que la escuela también es un lugar excluyente, el hecho de que muchos de ellos y ellas a temprana edad sean expulsados de la protección de sus familias, lleva a que solo encuentren en el ámbito del rebusque y la prostitución desde temprana edad, las posibilidades para la subsistencia. (Pérez, 2013).

"Es que yo solo estudié hasta cuarto de primaria, me tocó salir de mi casa porque mi padrastro es muy homofóbico y machista y no permitió que una hija maricona estuviera ahí. Yo lo único que aprendí para ganarme la vida es esto del trabajo sexual. Quisiera a veces hacer otras cosas, pero la verdad ya no me veo estudiando".

(Entrevista mujer trans, Barranquilla- diciembre de 2016).

Para las mujeres trans en el Caribe, en lo laboral, existe un asunto de mayor vulnerabilidad frente a sus derechos, debido a que en su construcción de género, están marcando unas claridades que no son negociables con el autocontrol ni con la censura. Sumado a que la gran mayoría, no cuentan 
con el apoyo de sus familiares para su desarrollo económico y no han accedido al sistema educativo, que les permita ejercer un rol profesional.

Los procesos de construcción permanente de identidad de género que viven las personas trans es un asunto que la sociedad aún desconoce, se sigue asociando a una patología y a una disforia de género; lo que ha conducido a construir una imagen errónea, excluyente y transfóbica para el caso de esta investigación, de las mujeres trans.

Eliminación en el proceso de selección: Frente a la eliminación de los procesos de selección se ha encontrado en esta investigación, que son personas trans y mujeres lesbianas quienes de manera significativa se enfrentan a este proceso de exclusión. Ello argumentado en estereotipos de género que determinan para el caso de las mujeres unos esquemas de estética, maquillaje y feminidad que determinan una "buena presentación" a la hora de asistir a una entrevista. Las mujeres expresan que en los espacios laborales los dispositivos hacia sus cuerpos son mucho más excluyentes que hacia el de los hombres.

Frente al acceso al trabajo en procesos de selección las mujeres entrevistadas afirman que el tema de exclusión está asociado no solo a concepciones homofóbicas o lesbofóbicas, sino también a estereotipos de género, "tan asentados y engendrados en la sociedad", donde las mujeres tienen que ser y comportarse femeninamente y quien se salga de ese marco, sencillamente no es contratada o no pasa el proceso de selección: frente a ello, la ausencia de información sistematizada se convierte en un obstáculo puesto que no se puede demostrar que "fui descartada" por mi expresión de género o mi orientación sexual; en ese aspecto termina siendo un tema que se comenta solo entre amigas, que permanece en el silencio o que en últimas, no se reconoce como una problemática porque la ausencia de pruebas estadísticas, invisibiliza la experiencia vivida y las construcciones intersubjetivas de estereotipación en el mundo laboral. (Pérez, Correa y Castañeda, 2013).

En los espacios laborales el maquillaje y el vestuario estandarizado por la moda como femenino (jean ajustado, falda, zapatos de tacón, cabello largo) operan como una norma social que prima sobre las actitudes y capacidades de las mujeres, en trabajos históricamente asociados a ellas, como secretaria, recepcionistas, atención al público, entre otros, la presión frente a ello es mucho más fuerte; las mujeres expresan que en las entrevistas de trabajo es lo primero que se mira y si no se cumple con esos patrones, es excluida 
con cualquier pretexto, incluyendo afirmaciones como "mala presentación"; de esta manera para el caso de las mujeres que independientemente de su orientación sexual se vean como muy masculinas, "machorras", son excluidas de esos oficios pensados como femeninos y se piensan en oficios y trabajos que requieren rudeza o fuerza física. En el país está muy marcada la segmentación de oficios para las mujeres masculinizadas en espacios como la vigilancia privada, recolectoras de basura u oficios más informatizados asociados con la carga y transporte.

"Yo estuve postulada para trabajar en Transcaribe y conmigo había otras cinco mujeres más, algo masculinas, sin maquillaje y de contextura gruesa, así como la mía y fue muy particular porque a nosotras nos dijeron que aplicáramos para trabajos en campo, para ponernos a sostener las paletas para indicar el flujo vehicular; en mi caso ni siquiera miraron que yo tenía un nivel de formación profesional, pues eso ahí no interesaba... Obviamente me sentí excluida y nada... en este momento estoy desempleada y sé que para un próximo trabajo tengo que ir como toda una "gallinita" para que al menos se fijen en mi hoja de vida." (Entrevista mujer lesbiana, Cartagena, octubre 2013).

Aplazamiento de la de-construcción de género: El aplazamiento en la construcción de género, pareciera ser una única posibilidad identificada por las mujeres trans entrevistadas, para poder lograr metas educativas y laborales en la vida, es decir, es preferible asistir a la universidad y tener un primer trabajo pareciendo un chico gay o mujer lesbiana que mostrarse públicamente como trans, puesto que según las personas entrevistadas existe menos prejuicios sociales sobre la orientación sexual que sobre la identidad del género, en alguna medida porque la primera puede ser más camuflada que la segunda.

Es común encontrar que las pocas mujeres trans que han logrado estudiar y tener cargos profesionales o empleos en sus profesiones, se debe a que aplazaron su tránsito al género deseado hasta el momento de sentir que tenían o habían logrado ganar reconocimiento y credibilidad frente a su profesión.

"Yo hasta el octavo semestre en la Universidad de Cartagena me comporté como un niño, que me veía muy femenino pero seguía siendo un hombre, solo fue hasta ese momento cuando me sentía empoderada con mi formación que empecé a realizar mi tránsito, a ser lo que verdaderamente soy; sin 
embargo soy consciente que ahora lo difícil va ser encontrar trabajo en mi profesión".

(Entrevista mujer trans, Cartagena, septiembre de 2016).

Autoempleo forzado: En esta investigación se entiende el autoempleo forzado para la población LGBT, como la única forma de integrarse en el mercado laboral trabajando en ciertos sectores en los que se considera adecuados, no tanto por su formación o por las expectativas de negocio que se prevean, sino porque es ahí donde puede reconocerse y medianamente ser respetados por su orientación sexual o identidades de género. Si bien, en la mayoría de los contextos el autoempleo es potencializador de autonomía y un importante elemento dinamizador del mercado laboral a partir de la creación de puestos propios de trabajo; en el contexto de la población LGBT entrevistada, se convierte en muchos casos en un asunto forzado, producto en la mayoría de las ocasiones, de discriminaciones a las que son sometidos en los ambientes laborales en los que dependería de un contrato y un empleador.

En este proceso de investigación se encuentra que de la población LGBT son los hombres gays de estratos pobres y mujeres lesbianas masculinas, quienes de forma significativa reconocen que su única salida en el medio laboral es generar sus propias condiciones de trabajo. Los primeros argumentan un temor de hacer visible su orientación sexual puesto que en los sectores en los que habitan se expresan prácticas abiertamente prejuiciosas y homofóbicas hacia los homosexuales y en el caso de las mujeres por un asunto de estética y feminidad que ha estereotipado a la mujer en los lugares de trabajo.

Para el caso de los hombres gays pertenecientes a los estratos uno, dos y tres, se encuentra que antes que tener que hacer visible su orientación sexual en los lugares de trabajo y por las dificultades que expresan para conseguir un empleo formal, muchos de ellos optan por elegir formas de autoempleabilidad, y actividades en la economía informal.

En el caso de las mujeres lesbianas, además del nivel educativo, el estrato socioeconómico entre otros, existe una exigencia social que se han instaurado en el imaginario colectivo, que de entrada excluye a muchas de ellas y tiene que ver con el asunto de la feminidad, del estar "bien presentadas", lo que ha llevado a que muchas se vean obligadas a generar, según su nivel socioeconómico, espacios de rebusque, economía informal o montar empresa. 
La calle como forma de rebusque y prostitución: Para la población trans es común encontrarse una serie de discursos y prácticas de exclusión en diferentes ámbitos de la vida humana y el acceso al trabajo no escapa de ello, en ese sentido, expresan, que se va configurando un sentimiento de minusvalía frente a los otros y frente a sí mismo; el rechazo en la familia, la escuela y en el mundo del trabajo les deja como única opción, en muchos de los casos, el trabajo sexual en las calles y el mercado de la informalidad. Sumado a ello, quienes logran prepararse académicamente para poder trabajar en su profesión u oficio tienen que esconder su identidad de género y para quienes, no pueden o quieren esconderse, lo único que se ofrece es la calle y la informalidad.

En el país y específicamente en la región, las personas trans se ven afectadas por una alta tasa de desempleo; muchas de ellas no tienen acceso a la educación formal; situación que lleva a la mayoría de ellas a "someterse" al trabajo sexual e incluso a la explotación sexual como único modo de subsistencia.

Según el INADI (2016) en una investigación reciente realizada en Argentina, pero que tiene conexiones con la realidad nuestra, existe una gran presión social hacia los y las adolescentes trans al momento de asumir su expresión de género, porque se sabe de las enormes dificultades que afrontarán debido al peso de la transfobia y la discriminación aún existentes en el ámbito laboral. Los niveles de escolaridad y de culminación de sus estudios se encuentran muy por debajo de la media, y podríamos decir que esto es producto de la transfobia existente en el sistema educativo, de las situaciones de violencia y discriminación entre sus pares, que derivan en su exclusión del sistema. Estas situaciones han comenzado, en la mayoría de los casos, en sus núcleos familiares.

No existen espacios laborales donde puedan estar las mujeres trans, salvo la peluquería y el trabajo sexual. Los imaginarios y prejuicios que la sociedad tiene frente al tema trans, se manifiestan en que se les asocia con prácticas de delincuencia. Este prejuicio lleva a que se tengan reservas para contratar mujeres trans, incluso en peluquerías, ello ha obligado a muchas asumir el trabajo sexual como "única salida".

La calle es un escenario de vulneración de derechos, de revictimización y se ha convertido en uno de los pocos espacios donde las mujeres trans pueden autoreconocerse y vivir en y desde su identidad de género. Sin embargo, 
6 La entiendo como una actitud que se emplea para justificar el maltrato, la discriminación y el abuso de personas que no se ajustan a la heterosexualidad normalizada; como consecuencia, muchas de ellas interiorizan esta actitud, lo que les provoca una negación de sus propias identidades. Al respecto véase Warner (1993).

7 Por hipersexualización de la identidad, entiendo un patrón de exaltación de la sexualidad de las personas LGTB por sobre otras dimensiones y aspectos de su identidad, o la sexualización de sus expresiones, posturas o actitudes (KEMPADOO, 2004). trae consigo unas discriminaciones adicionales, vinculadas a connotaciones estéticas y de hiperfeminización que hacen a unas las mujeres trans en los ejercicios de la prostitución, más vulnerables y vulnerados que a otras.

"A mí me toca el rebusque, así he vivido, que un servicio aquí, la peluquería por días, un cliente por allí... uno como trans no la tiene fácil... la calle me ha enseñado mucho, me ha hecho entender que hay gente que odia sin conocer a la persona y mi gran temor es cuando ya no tenga juventud quién me va a buscar para un servicio".

(Entrevista mujer trans, Cartagena de Indias, noviembre de 2016).

\section{Consideraciones finales}

$\checkmark$ on base en los relatos y experiencias vividas compartidas por personas LGBT y empleadores en las ciudades de Barranquilla y Cartagena, podría finalizar reafirmando que muchas de las discriminaciones por orientación sexual e identidades de género en los espacios laborales persisten, reproducen y justifican socialmente a pesar de avances jurídicos y normativos en el país.

En el plano cultural muchos espacios laborales continúan siendo definidos y concebidos desde una lógica hegemónicamente masculinizada, por lo que muchas de las acciones presentadas en este artículo siguen siendo reproducidas sistemáticamente y se han instaurado en prácticas soterradas, naturalizadas y en la mayoría de veces, terminan siendo ocultas.

En este ejercicio investigativo, encontramos que el rechazo hacia las identidades LGBT en espacios laborales en las ciudades mencionadas, se expresa en actitudes, enunciados y comportamientos culturales que reproducen prejuicios y estereotipos de género contra aquellas personas que no responden a los roles esperados socialmente desde la lógica binaria; en este sentido se observa como la heteronormatividad ${ }^{6}$ puede provocar situaciones de discriminación sobre trabajadores y trabajadoras LGTB que expresen su identidad sexual o de género, o puede condenarlos a "permanecer en el closet" o aplazar su transición en el caso de las personas trans.

Los prejuicios y/o estereotipos hacia las personas LGBT les condena en muchas ocasiones a lo que podríamos denominar como una representación del Otro en términos de hipersexualizar su identidad ${ }^{7}$ donde como se ha venido mencionando se establecen roles y funciones socialmente según la identidad 
percibida, pero también se exige que se debe demostrar por ejemplo que "un empleado gay aun siendo gay puede cumplir con su función como cualquier otro trabajador".

\section{REFERENCIAS BIBLIOGRÁFICAS}

Bourdieu, Pierre (2000). La dominación masculina. Buenos Aires: Anagrama.

Butler, Judith (1993). Cuerpos que importan. Sobre los límites materiales y discursivos del «sexo». Buenos Aires: Paidós.

Butler, Judith (2006). Deshacer el género. Barcelona: Paidós.

Chakrabarty, Dipesh (2008). Al margen de Europa. México: Tusquets Editores.

Chung, Barry (1998). Discrimination and identity management in career counseling with sexual minorities Paper presented at the American Psychological Association Annual Convention, San Francisco.

Gómez, María Mercedes (2008). Violencia por prejuicio sexual. Capítulo VIII. En: la Mirada de los jueces: Sexualidades diversas en la jurisprudencia latinoamericana. Tomo II. Siglo del Hombre, Bogotá.

Foucault, Michel (2000). Los anormales. Buenos Aires: Fondo de Cultura Económica.

Frazer, Nancy (1997). Iustitia interrupta. Reflexiones críticas desde la posición poscolonialista. Bogotá: Siglo Editores.

Instituto Nacional contra la Discriminación, la Xenofobia y el Racismo - INADI (2016). Diversidad sexual en el ámbito del trabajo: guía informativa para sindicatos; dirigido por Javier Alejandro Bujan. Primera edición. Ciudad Autónoma de Buenos Aires.

Merlau, Ponty (1997). Fenomenología de la percepción. México: Fondo de Cultura Económica.

Kempadoo, Kamala (2004). Sexing the Caribbean: gender, race and sexual labor. $1^{\text {a }}$ ed. New York: Routledge.

Le Blanc, Guillaume (2007). Vidas ordinarias, vidas precarias. Barcelona: Nueva Visión.

Luhmann, Niklas (1995). Poder. Barcelona: Átropos.

Machín, Juan (2013). Análisis conceptual de las discriminaciones desde un enfoque antropológico. Ponencia presentada en el seminario para la formación de una ciudadanía a favor del derecho a la igualdad y la no discriminación en la Ciudad de México. Consejo para Prevenir y Eliminar la Discriminación de la Ciudad de México (COPRED). En: https://es.scribd.com/doc/145766832/ Discriminacion-un-enfoque-antropologico 
OIT (2012). La discriminación en el trabajo por motivos de orientación sexual e identidad de género: Resultados del proyecto PRIDE de la OIT. En: http://www.ilo.org/wcmsp5/groups/public/ dgreports/gender/documents/briefingnote/wcms_380831.pdf

Ortner, Sherry B. (2009). Resistencia densa: muerte y construcción cultural de agencia en el montañismo himalayo. En: Papeles de trabajo. Revista Electrónica del Instituto de Altos Estudios Sociales de la Universidad Nacional de General San Martín. ISSN: 1851-2577. Año 2, nº 5, Buenos Aires, junio de 2009.

Passeron, Jean-Claude (1991). Le raisonnement sociologique. France: Nathan.

Pérez, Alexander (2013). Evitar poner el grito en el cielo. Diversidad sexual e identidades de género en familias con prácticas patriarcales en Cartagena de Indias, 2010-2012. En: Revista Palobra.No 13. Universidad de Cartagena.

Pérez, Alexander; Correa, Guillermo \& Castañeda, Wilson (2013). Raros. Diversidad sexual y mundo laboral. Discriminación y exclusión. Medellín: Escuela Nacional Sindical.

Warner, Michael (1993). Fear of a queer planet: Queer politics and social theory, Minneapolis, University of Minnesota, 1993.

Wallerstein, Immanuel (2006). Análisis de sistemas-mundo. Una introducción, España: Siglo XXI Editores. 

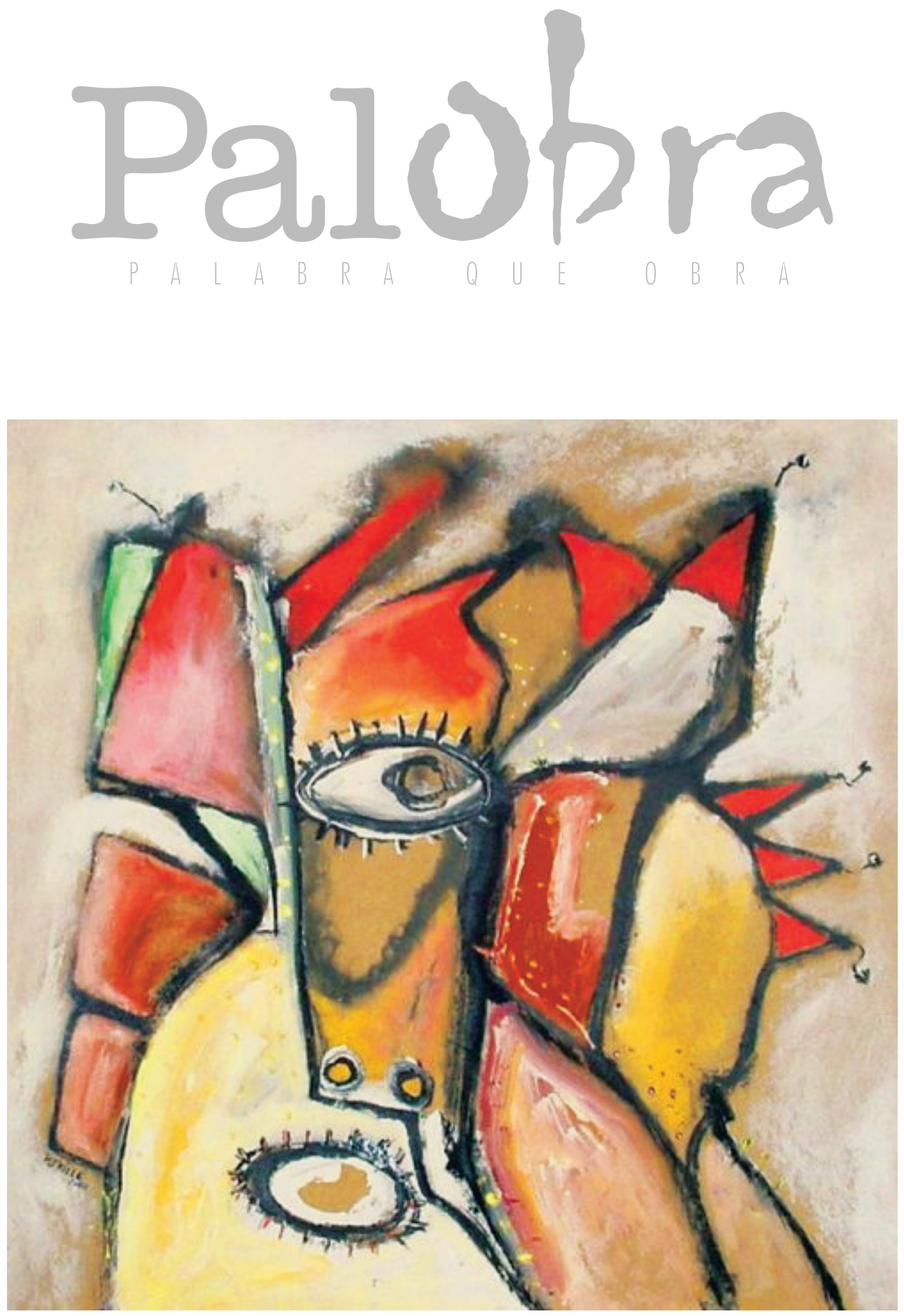

Obra pictórica de la serie "Rostros" de Eduardo Potrillé 